\title{
The Effect of Control Mechanism on Relational Performance in China's Petrochemical Industry
}

\author{
Hong JIN \\ School of Business, Jiangxi Normal University, Jiangxi, China \\ Yudong ZHANG \& Huilong ZHANG \\ Master Candidate, School of Business, Jiangxi Normal University, Jiangxi, China
}

\begin{abstract}
For this empirical study surveying the author selected 232 samples of Chinese buyers who are still importing petrochemical products and have already done business with foreign vendors for more than 3 months. As the result, the level of control mechanisms like Incentive, Favors and Socialization used by suppliers do strengthen the economic and emotional commitment of buyers towards suppliers, but the surveillance one of the control mechanisms used by suppliers has no influence on the dimension of commitment of buyers towards suppliers.
\end{abstract}

KEYWORD: Control Mechanism; Relational Performance; Commitment

\section{INTRODUCTION}

This research is based on petrochemical industry in China, and the primary purpose of the study is to review the characteristics of relationship between Chinese buyers and Korean suppliers after understanding the influence of control mechanism by change of 'paradigm' towards long-term collaborative relationship and mutual performance between buyers and suppliers. For this empirical study surveying the author selected 232 samples of Chinese buyers who are still importing petrochemical products and have already done business with foreign vendors for more than 3 months. Finally, the author discussed some theoretical contributions and managerial implications. And then, the author presented limitations of this study and the future research directions.

\section{LITERATURE REVIEW}

Enterprises utilize various mechanisms in order to control the diversified opportunism. Jap and Ganesan (2000) assorted control mechanism that protects retailers' transactional specific assets into trans-action specific investment (Anderson and Weitz 1992), relational norms (Heide and Joh 1992; Macneil 1980), monitoring (Lal 1990), qualification procedures (Stump and Heide 1996) etc. Heide and John (1990) pointed out that to identify counterparts' capability and motivation is the essential control mechanism as it is very difficult to change counterpart for the sake of transaction specific assets. An evaluation on the suppliers' is conducted in two aspects. First, evaluating suppliers' benevolence (Ganesan 1994). Second, evaluating the intention of presenting incentives to buyers. Wathne and Heide (2000), in other researches, proposed that opportunism's control mechanism generally fall into four categories: monitoring, incentive, selection and socialization, and they also made comparisons between control mechanism's aim, precondition and their effects.

Likewise, researchers know that enterprises use various mechanisms so as to dominate the transactions (Bradach and Eccles 1989). A couple of cases showed that these mechanisms have been different from one other or they have been functionally alter-native (Stump and Heide 1996). In other words, it means that multi-mechanism have been used at the same time (Nevin 1995), and many researches on these multi-mechanisms have been conducted (Anderson 1988). Control mechanisms, some-times, are utilized to take advantage of the various effects (Bradach 1997).

In this study, we focus on control mechanism's benevolence, incentive, monitoring and socialization. The first reason is that all of these four control mechanisms have been recognized as important theories in previous studies. In addition, in the Chinese market where Guanxin is highly emphasized, the transactional relationship is regarded as very important variables. Therefore, it is especially significant to understand what kind of 
methods are needed in Chinese market in the aspect of effectiveness.

\section{RESEARCH HYPOTHESIS}

\subsection{The effects of supplier's incentive for buyers on relationship commitment}

Wathne and Heide (2000) proposed opportunistic control mechanism as incentive. By requiring security, adjusting the price or margins, incentives induces the counterparts to give up opportunistic behaviors by themselves and offer cooperation (Kaufmann and Lafontaine 1994).

Furthermore, by providing incentives, the other party controls the active opportunism (Wathne and Heide 2000), which could not only establish cooperative transaction relationship, but also bring the effect of cost reduction and profit increase by utilizing incentives. Relationship commitment is eventually built by the method of handling the issues of risks and cost reduction, and showing their willingness for sharing of the profit (Burt 1992). Buyers, therefore, can form the economic commitment by realizing cost reduction and profit increase.

H1: The level of suppliers' incentives has positive effects on buyers' affective commitment to the suppliers.

$\mathrm{H} 2$ : The level of suppliers' incentives has positive effects on buyers' economical commitment to the suppliers

\subsection{The effects of buyers' benevolence to suppliers on the relationship commitment}

When perceived supplier's benevolence, buyers will become dependent on the supplier's capability and trust and will probably form the long-term transactional relationship. That is to say, suppliers will do their utmost to receive the buyers' trust and establish long-term relationship. Benevolence can be perceived as friendly acts beyond the situation of contract or promise and could probably arise emotional affective arousal or even excitement and this can lead to the positive emotional response (Selnes and Gonhaug 2000). Therefore, benevolence will have positive effects on emotional commitment.

H3: The level of supplier's benevolence has positive effects on buyer's affective commitment to supplier.

H4: The level of supplier's benevolence has positive effects on buyer's economical commitment to supplier.

\subsection{Supplier's monitoring of buyer and its effects on relationship commitment}

Monitoring is to observe the other party if they are abide by the established behaviors or performance standard (Wathne and Heide 2000). This reduces the problems that result from the information asymmetry when one party can not obtain the other party's performance and behaviors.

Monitoring the other party's behavior or the consequence of it can relieve the information asymmetry among the channel members and furthermore, can overcome the problems aroused by the channel member's opportunistic actions(Celly and Frazier 1996). Though, monitoring sometimes occurs the other party's unpleasant feelings, it has the effects of driving one's own motivations to do the utmost with the roles given. Without monitoring, there will al-ways the risks result from troubles in decision-making, lack of others' understanding and trust, opportunistic behaviors from information asymmetry (Lee, Park, Lim 2002).

H5: The level of supplier's monitoring has positive effects on buyer's affective commitment to supplier.

H6: The level of supplier's monitoring has positive effects on buyer's economic commitment to supplier.

\subsection{Supplier's socialization and its effects on relationship commitment}

Socialization is the homogeneous definition of adaptation between organizations or cultural convergence (Das and Teng 1998). Through socialization one can make the other person's aim coincide with his own. Socialization can be regarded as the control method that brings two transactional parties into a cooperative relationship by sharing of common value and norms. Though, there have been insufficient researches on socialization's effects on direct relationship quality in distribution, most of them centered on communication as the core factors in integrating of the organizations that facilitating the building of long-term relationship. In addition, socialization has the effect of reducing opportunism. Socialization induces two parties' agreement on common goals they are seeking and the setting of common goals helps heterogenous organizations to integrate the their resources so as to make them more efficiently utilized (Das and Teng 1998).

H7: The level of supplier's socialization has positive effects on buyer's affective commitment to supplier.

H8: The level of supplier's socialization has positive effects on buyer's economical commitment to supplier. 


\subsection{Supplier's relationship commitment and its effects on relationship performance}

Relational performance is evaluated with its cost and related efficiency (Lusch and Brown 1996) or its financial performance such as return on investment, revenue, sales and cost reduction (Raven, McCullough, and Tansuhaj 1994). In this study, relational performance has focused on the transaction cost reduction, profitability and general financial performance.

Kalwani and Narayandas (1995) pointed out that firms who has established long-term transactional relationship have higher sales growth and lower inventory and control cost than those don't have. Therefore, if the buyer become aware of the supplier's cooperativeness and closed tied, they will show intention to continue with the relationship in future.

In other words, if the intention for continuing the relationship or the affective commitment to the supplier is high that resulted from the transaction cost and profit, positive cooperation will be built, and the buyer's relational performance will get enhanced.

H9: The level of supplier's affective commitment has positive effects on buyer's relational performance.

H10: The level of supplier's economical commitment has positive effects on buyer's relational performance.

\section{RESEARCH METHOD}

\subsection{Research design and data collection}

The purpose of this research is focused on the relationship between petrochemicals buyers and foreign suppliers. Therefore, we have chosen buyers who are purchasing and importing Chinese petrochemicals as our research subjects for conducting of surveys. A total of 251 questionnaires was distributed and 237 was collected. 5 of the insignificant or inappropriate questionnaires was deleted and 232 was used for statistical analysis.

\subsection{Statistical methods}

Measurement model's validity was tested by testing latent variable. Then, the rest of the items was used to evaluate the validity of the measurement model. That is to say, confirmative factor analysis was conducted with all of the latent variables and measurement variables included in the model. Amos (Analysis Moment of Structure) was used to examine convergent validity and discriminant validity. After examining the reliability and validity focusing on research hypothesis, SEM(Structural Equation Modeling)was used to have an overall examination of the model. To achieve this, statistical program AMOS18.0 was used to test the fitness index. Not only can this method differentiate research model's fitness, but also the causal-andeffect relationship between the constructs invented by the researchers can be tested.

\section{EMPIRICAL ANALYSIS}

\subsection{Data analysis and hypothesis examination}

Reliability analysis of variables:

Table 1. Results of variables' reliability

\begin{tabular}{|c|c|c|}
\hline factors & $\begin{array}{c}\text { number of } \\
\text { items }\end{array}$ & Cronbach's $\alpha$ \\
\hline supplier's incentives & 5 & 0.872 \\
\hline supplier's benevolence & 3 & 0.871 \\
\hline supplier's monitoring & 4 & 0.879 \\
\hline supplier's socialization & 4 & 0.871 \\
\hline buyer's affective commitment & 5 & 0.872 \\
\hline buyer's economical commitment & 3 & 0.873 \\
\hline buyer's relationship performance & 4 & 0.879 \\
\hline
\end{tabular}

Confirmative factor analysis: this research model consists of many latent variables that have been measured in various literatures. Confirmative factor analysis of the whole latent variables and each measurement variable were conducted, using AMOS 18.0. First of all convergent validity is associated with "to what extent does the measurement of the same constructs are consistent with multiple scale"(Bae Byung Ryul 2004). In general, if the standard factor loadings are greater than 0.5 , the convergent validity is satisfactory. In this research, confirmative factor analysis was conducted to test the convergent validity and the results shown in <Table 2> are between 0.540 0.930, which are higher than the standard value 0.54 , meaning the convergent validity are satisfactory.

\subsection{Test of the research model and hypothesis}

In order to test the research model's overall fit, Amos 18.0 were used and the index of goodness of fit of proposed model were tested. Looking into the overall fit of the research model, the statistics show that $\chi^{2}$ is 465.258 and $\mathrm{df}$ is $329(\mathrm{p}=.000)$. When the number of sample exceeds 200 , the statistics of $\chi^{2}$ has the tendency to turn insignificant, therefore, it is general way to take into consideration the other fitness index and give a comprehensive judgement. The results of the fitness measurement are GFI(0.88), RMR(0.10), AGFI(0.86), CFI(0.93), NFI(0.84), RMSEA(0.05) and so on. The results fell into the acceptable ranges. 
Table 2. Results of confirmative factor analysis

\begin{tabular}{|c|c|c|c|c|}
\hline dimension & items & loadings & \begin{tabular}{|c|} 
standard factor \\
loadings
\end{tabular} & t-value \\
\hline \multirow{5}{*}{ incentive } & Incen1 & 1.000 & 0.707 & - \\
\hline & Incen2 & 0.916 & 0.640 & 8.444 \\
\hline & Incen3 & 0.828 & 0.541 & 7.252 \\
\hline & Incen4 & 0.889 & 0.681 & 8.920 \\
\hline & Incen5 & 0.705 & 0.586 & 7.799 \\
\hline \multirow{3}{*}{ benevolence } & benev1 & 1.000 & 0.730 & - \\
\hline & benev2 & 1.314 & 0.930 & 12.331 \\
\hline & benev3 & 1.052 & 0.753 & 11.093 \\
\hline \multirow{4}{*}{ monitoring } & mon1 & 1.000 & 0.761 & - \\
\hline & mon2 & 0.896 & 0.775 & 11.012 \\
\hline & mon3 & 0.786 & 0.613 & 8.749 \\
\hline & mon4 & 1.136 & 0.806 & 11.328 \\
\hline \multirow{4}{*}{ socialization } & socia1 & 1.000 & 0.668 & - \\
\hline & socia2 & 1.275 & 0.782 & 9.755 \\
\hline & socia3 & 1.344 & 0.785 & 9.775 \\
\hline & socia4 & 1.021 & 0.575 & 7.592 \\
\hline \multirow{5}{*}{$\begin{array}{c}\text { affective } \\
\text { commitment }\end{array}$} & affec 1 & 1.000 & 0.789 & - \\
\hline & affec2 & 1.029 & 0.732 & 10.863 \\
\hline & affec3 & 0.810 & 0.627 & 9.211 \\
\hline & affec4 & 0.853 & 0.654 & 9.642 \\
\hline & affec5 & 0.934 & 0.659 & 9.720 \\
\hline \multirow{3}{*}{$\begin{array}{c}\text { economical } \\
\text { commitment }\end{array}$} & econ1 & 1.000 & 0.540 & - \\
\hline & econ 2 & 1.005 & 0.619 & 6.225 \\
\hline & econ3 & 1.595 & 0.671 & 6.461 \\
\hline \multirow{4}{*}{$\begin{array}{l}\text { relationship } \\
\text { performance }\end{array}$} & per1 & 1.000 & 0.626 & - \\
\hline & per2 & 1.249 & 0.775 & 8.952 \\
\hline & per3 & 1.232 & 0.792 & 9.054 \\
\hline & per4 & 1.117 & 0.731 & 8.633 \\
\hline $\begin{array}{l}\text { goodness } \\
\text { of fit }\end{array}$ & \multicolumn{4}{|c|}{$\begin{array}{c}\chi^{2}=371.642(\mathrm{P}=0.000), \mathrm{df}=222, \mathrm{GFI}=0.878 \\
\mathrm{CFI}=0.944, \mathrm{RMR}=0.073, \mathrm{RMSEA}=0.042\end{array}$} \\
\hline
\end{tabular}

In order to conduct a test on hypothesis, structural model was designed and path analysis was carried out. For this purpose, AMOS 18.0 was used for analysis. Of the 8 path coefficient, only H5 and H6 were not supported by the. Therefore, the other 6 hypotheses are supported. To be more specifically, first, under the effect of control mechanism variable on relation-ship quality variable, the effects of petrochemical supplier's incentives level on Chinese buyers' affective commitment was examined. The supplier's incentive level positively affected buyer's affective commitment (H1 supported, $\beta=0.32$, $\mathrm{t}=4.65$ ), and in addition, the hypothesis that supplier's level of incentive have positive effects on buyer's economical commitment on supplier was tested ( $\mathrm{H} 2$ supported, $\beta=0.26, \mathrm{t}=3.91)$. Supplier's benevolence on buyers has positive effects on buyer's affective commitment to the supplier (H3 supported, $\quad \beta=0.17, \quad \mathrm{t}=2.92)$. And, supplier's benevolence on buyers has positive effects on buyer's economical commitment to supplier (H4 supported, $B=0.15, \mathrm{t}=2.87$ ). Additionally, the effect of supplier's monitoring level on buyer's relationship commitment to suppliers was examined. We found that supplier's monitoring level didn't positively affected buyer's affective commitment to suppliers (H5 not supported, $B=-0.08, t=-0.75$ ), nor the buyer's economical commitment to suppliers (H6 not supported, $\beta=0.18, \mathrm{t}=1.80)$.

Finally, the effect of supplier's socialization level on buyer's relationship commitment to suppliers was tested. The results showed that supplier's socialization level positively affected buyer's affective commitment to suppliers (H7 supported, $\beta=0.32, t=3.53$ ) and also positively affected buyer's economical to suppliers(H8 supported, $\beta=0.18$, $\mathrm{t}=2.32$ ). Second, relationship quality variable's effects on buyer's relationship commitment was tested. It was found that buyer's affective commitment to suppliers positively affect buyer's relationship performance ( $\mathrm{H} 9$ not supported, $B=0.11$, $\mathrm{t}=2.51$ ), and buyer's economical commitment to suppliers positively affected buyer's relationship performance as well (H10 supported, $\beta=0.23$, $\mathrm{t}=3.04$ ).

\section{CONCLUSION}

By focusing on the buyer-seller relationship, this research has chosen the distribution channel between Chinese petrochemical buyers and foreign suppliers as the research object. Based on the Chinese petrochemical industry, we managed to shed light on the control mechanism variables that affect Chinese buyers' relationship commitment to foreign suppliers. And empirical studies on the effects of control mechanism (incentive, benevolence, monitoring and socialization) that developed between buyer and supplier on buyer's economical commitment and affective commitment was conducted. Additionally, these control mechanism's effects on buyer's relationship performance was tested via relationship commitment dimension.

\section{REFERENCES}

[1] Genfen, D (2002), "Reflections on the Dimensions of Trust and Trustworthiness among Online Customers," ACM SIGMIS Database, 33(3), 38-53.

[2] Gummesson, E. (2002), "Relationship Marketing in the New Economy", Journal of Relational Marketing, 1(1), 37 57.

[3] Wathne, Kenneth H. and Jan B. Heide (2000), "Opportunism in Interfirm Relationships: Forms, Outcomes, and Solutions," Journal of Marketing, 64 (October), 36-51. 